\title{
O ACOMPANHANTE NO MOMENTO DO TRABALHO DE PARTO E PARTO: PERCEPÇÃO DE PUÉRPERAS*
}

Andressa Suelly Saturnino de Oliveira ${ }^{1}$, Dafne Paiva Rodrigues² ${ }^{2}$ Maria Vilaní Cavalcante Guedes ${ }^{2}$, Gilvan Ferreira Felipe $^{3}$, Francisca Tereza de Galiza', Lidiane Colares Monteiro ${ }^{3}$

\begin{abstract}
RESUMO: Estudo descritivo, qualitativo, realizado em hospital público de nível secundário em Fortaleza - Ceará, com 14 puérperas, com o objetivo de analisar sua percepção acerca da presença/participação do acompanhante durante o trabalho de parto e o parto. A coleta de dados aconteceu entre agosto e setembro de 2009, por meio de entrevista semiestruturada gravada e as falas foram organizadas e analisadas com base na análise de conteúdo. As atividades desempenhadas pelos acompanhantes foram conversar, proporcionar apoio e segurança e explicar eventos desconhecidos. A importância da participação do acompanhante se centrou na minimização dos sentimentos de solidão que se somavam às dores das parturientes. Verificou-se o valor atribuído à escolha de pessoas conhecidas, com destaque para as mães. Concluiu-se que o cuidado proporcionado pelos acompanhantes se mostrou imprescindível para garantir conforto e bem-estar às mulheres no momento da parturição.
\end{abstract}

PALAVRAS-CHAVE: Parto humanizado; Trabalho de parto; Acompanhantes de pacientes.

\section{THE COMPANION DURING LABOUR AND BIRTH: NEW MOTHERS' PERCEPTIONS}

ABSTRACT: A descriptive, qualitative study carried out in a second-level public hospital in Fortaleza-Ceara, with 14 new mothers, with the objective of analyzing their perceptions of the presence/participation of companions during labor and childbirth. Data were collected between August and September 2009, via recorded semi-structured interviews, and the exchanges were organized and analyzed based on their contents. Activities carried out by companions were conversing, providing support and security, and explaining unfamiliar events. The importance of the companion's participation lay in the minimization of feelings of loneliness which added to the pain the mothers-to-be were going through. The value of choosing acquaintances was noted, with most women choosing their mothers. It was concluded that the care provided by the companions showed itself to be invaluable in providing comfort and well-being to the women during childbirth.

KEYWORDS: Humanized childbirth; Labor; Patients' companions.

\section{EL ACOMPAÑANTE EN EL MOMENTO DEL TRABAJO DE PARTO Y PARTO: PERCEPCIÓN DE PUÉRPERAS}

RESUMEN: Estudio descriptivo, cualitativo, realizado en hospital público de nivel secundario en Fortaleza - Ceará, con 14 puérperas, con el objetivo de analizar su percepción acerca de la presencia/participación del acompañante durante el trabajo de parto y el parto. Los datos fueron recogidos entre agosto y septiembre de 2009, por medio de entrevista semiestructurada grabada y las hablas fueron organizadas y analizadas con base en análisis de contenido. Las actividades desempeñadas por los acompañantes fueron charlar, proporcionar apoyo y seguridad y explicar eventos desconocidos. La importancia de la participación del acompañante se ha centrado en la minimización de los sentimientos de soledad que se añadieron a los dolores de las parturientas. Se verifico el valor atribuido a la elección de personas conocidas, en especial para las madres. Se concluyó que el cuidado proporcionado por los acompañantes se mostró imprescindible para garantizar confort y bienestar a las mujeres en el momento del parto.

PALABRAS CLAVE: Parto humanizado; Trabajo de parto; Acompañantes de pacientes.

\footnotetext{
* Pesquisa resultante de Monografia de Conclusão do Curso de Graduação em Enfermagem da Universidade Estadual do Ceará - UECE. ${ }^{1}$ Enfermeira. Mestranda em Cuidados Clínicos em Saúde da UECE. Bolsista CAPES.

${ }^{2}$ Enfermeira. Doutora em Enfermagem. Professora do Curso de Mestrado em Cuidados Clínicos em Saúde da UECE. Tutora do Programa de Educação Tutorial/Enfermagem da UECE.

${ }^{3}$ Enfermeiro. Mestrando em Cuidados Clínicos em Saúde da UECE. Bolsista da Fundação Cearense de Apoio ao Desenvolvimento Científico e Tecnológico - FUNCAP.
}

Autor correspondente:

Andressa Suelly Saturnino de Oliveira

Universidade Estadual do Ceará

R. Alice, 222 - 60822-610 - Fortaleza-CE-Brasil

E-mail: andressasuelly@hotmail.com

Recebido: $08 / 12 / 10$

Aprovado: $30 / 03 / 11$

Cogitare Enferm. 2011 Abr/Jun; 16(2):247-53 


\section{INTRODUÇÃO}

Conhecidos são os relatos de mulheres sobre o parto que, além de ansiedade, curiosidade e expectativa, revelam medo frente à dor. Histórias de partos difíceis são contadas às mulheres desde a infância, sendo repassadas por gerações, culminando na constituição da cultura do medo do parto. Essa cultura se personifica nos relatos da maioria das gestantes que caracterizam o momento da parturição como algo doloroso, assustador, um enfrentamento da morte ${ }^{(1-2)}$.

A discussão sobre a simbolização do parto para a mulher perpassa pela comparação do parto domiciliar realizado, antigamente, por parteiras, com o parto hospitalar, praticado atualmente. No século XIX, o parto era uma vivência íntima que acontecia com o apoio de outras mulheres que se esforçavam para proporcionar à parturiente o maior conforto possível durante esse evento $^{(3)}$.

No contexto atual, o medo de sofrer durante o parto, além de assustar as mulheres, impõe-lhes uma vivência de solidão em um ambiente desconhecido e no qual são cercadas por pessoas estranhas. Ao ser internada, a mulher passa a ser um caso, recebe um número de registro para sua identificação, deixando de ser indivíduo; torna-se, então, mais uma na hora de parir. Na maioria das maternidades públicas a parturiente fica distante da família; em contrapartida, observa-se o despertar para a consideração do parto/nascimento como um evento familiar. Portanto, no cuidado à gestante, não se pode pensar apenas em mulher grávida, mas, também, em família grávida ${ }^{(2,4)}$.

O Ministério da Saúde reconhece que a presença do acompanhante traz benefícios e que as gestantes que contam com um acompanhante no parto e puerpério imediato ficam mais tranquilas e seguras durante o processo, havendo diminuição do tempo de trabalho de parto e do número de cesáreas. A permanência de outra pessoa junto à mulher contribui, ainda, com a redução do risco de acometimento por depressão pósparto. O acompanhante pode, também, ajudar a mulher nas tarefas básicas com o bebê no pós-parto, quando a mãe se encontra em fase de reabilitação. Com a sanção da Lei n. 11.108, em abril de 2005, recomenda-se que os serviços de saúde se reorganizem para incluir o acompanhante no período de trabalho de parto, parto e puerpério imediato. Essa intervenção busca garantir que toda parturiente tenha uma pessoa de sua escolha para confortá-la e encorajá-la durante o processo do nascimento $^{(5)}$.
Embora a presença do acompanhante seja uma recomendação do Ministério da Saúde, observam-se, em alguns serviços de saúde, obstáculos a sua participação, justificados pela inadequada infraestrutura $\mathrm{e}$, principalmente, pela falta de preparo da equipe de saúde para lidar com essa recomendação ${ }^{(6)}$.

Diante do exposto sobre o que se propõe para o cotidiano dos serviços de saúde que atendem à parturiente e o que é vivenciado por essas mulheres nas salas de parto, questiona-se: qual a percepção das puérperas sobre a presença/participação do acompanhante no trabalho de parto e parto? Sendo assim, este estudo teve por objetivo analisar a percepção de puérperas acerca da presença/participação do acompanhante durante o trabalho de parto e parto.

\section{METODOLOGIA}

Estudo descritivo, de natureza qualitativa, realizado em uma maternidade pública de nível secundário, localizada na área de abrangência da Secretaria Executiva Regional VI de Fortaleza, Estado do Ceará. A instituição é referência no atendimento obstétrico e neonatal do estado, realiza mensalmente cerca de 500 partos e adota preceitos do cuidado humanizado ao processo de parturição.

A pesquisa foi realizada com 14 puérperas da Unidade de Internação Obstétrica - Alojamento Conjunto. O número de participantes foi definido pela saturação teórica dos dados; houve suspensão da coleta quando os dados obtidos passaram a apresentar repetição, sem acréscimo de novas informações ao alcance do objetivo $^{(7)}$.

Os critérios de inclusão abrangeram primíparas e multíparas com idade acima de 18 anos, nascimento do filho por meio de parto normal (vaginal) no Centro Obstétrico da instituição em questão, nas primeiras 24 horas de puerpério e com condições físicas e psicológicas para responder às perguntas da entrevista. As puérperas que concordaram em fazer parte da pesquisa assinaram o Termo de Consentimento Livre e Esclarecido, após explicação sobre a finalidade do estudo.

O instrumento de coleta de dados, aplicado por meio de entrevista semiestruturada, abrangeu aspectos socioeconômicos da puérpera; antecedentes obstétricos; período de trabalho de parto após a admissão; vivência do trabalho de parto e parto e presença de acompanhante nesses momentos, cuidados prestados pela enfermeira e satisfação. 
Os dados foram coletados nos meses de agosto e setembro de 2009, após aprovação de projeto pelo Comitê de Ética em Pesquisa da Universidade Estadual do Ceará, com parecer n. 09144194-3/2009. As entrevistas foram gravadas e os depoimentos foram organizados e trabalhados com base na técnica de Análise de Conteúdo, que apresenta três etapas: pré-análise, exploração do material e tratamento dos resultados obtidos, e interpretação ${ }^{(8)}$. Esse método foi selecionado para classificar os grupos de elementos a partir de títulos genéricos, cujo agrupamento foi realizado segundo as características comuns dos elementos dos depoimentos.

A análise das falas das entrevistas convergiu para o estabelecimento de quatro categorias temáticas: o acompanhante como amenizador do sentimento de solidão; alguém conhecido e em quem pudessem confiar; atividades desempenhadas pelos acompanhantes; a presença de acompanhante não é importante.

Afim de garantir o anonimato das participantes, foram utilizados nomes fictícios. Considerando o que preconiza a Resolução n. 196/96 do Conselho Nacional de Saúde sobre Diretrizes e Normas Regulamentadoras de pesquisas envolvendo seres humanos, os princípios éticos foram respeitados em todas as fases da pesquisa ${ }^{(9)}$.

\section{RESULTADOS}

Conforme se verifica-se no quadro 1 , as participantes se situavam na faixa etária entre 18 e 32 anos; a maioria possuía escolaridade de ensino médio e vivia com o companheiro em regime de união consensual. Ao serem questionadas sobre o número de partos, observou-se diferença pouco significativa entre o número de primíparas (desconsiderando-se o parto atual) e multíparas.

Quadro 1 - Caracterização sociodemográfica e clínica das puérperas. Fortaleza, 2009

\begin{tabular}{|c|ccccccc|}
\hline Puérpera & Idade & $\begin{array}{c}\text { Situação } \\
\text { conjugal }\end{array}$ & Ocupação & Escolaridade & $\begin{array}{c}\text { Partos } \\
\text { anteriores }\end{array}$ & TP & Acompanhante \\
\hline Angélica & 29 & UC & Do lar & EF & 2 & 1 & Mãe \\
Bruna & 24 & Solteira & Doméstica & EF & 2 & 1 & Amiga \\
Cecília & 24 & UC & Do lar & EM & 1 & 3 & Cunhada \\
Daniela & 21 & UC & Do lar & EM & 1 & 3 & Mãe \\
Eliana & 18 & UC & Do lar & EF & 2 & 4 & Sogra \\
Fabíola & 18 & UC & Do lar & EM & 1 & 1,5 & Mãe \\
Géssica & 21 & UC & Do lar & EM & 2 & 0,5 & - \\
Helena & 18 & UC & Do lar & EF & 1 & 0,5 & Mãe \\
Ingrid & 20 & UC & Do lar & EF & 4 & 3 & Companheiro \\
Joana & 21 & UC & Cabeleireira & EM & 1 & 2,5 & Mãe \\
Larissa & 28 & Solteira & Do lar & EM & 1 & 8 & Mãe \\
Melissa & 32 & UC & Do lar & EF & 5 & 4,5 & - \\
Natália & 19 & UC & Estudante & EM & 1 & 3 & Mãe \\
Olívia & 22 & UC & Do lar & EM & 1 & 5 & - \\
\hline
\end{tabular}

Legenda: UC - União Consensual; EF - Ensino Fundamental; EM - Ensino Médio; TP - Tempo de trabalho de Parto, em horas, a partir da admissão hospitalar.

O acompanhante como amenizador do sentimento de solidão

No que diz respeito às participantes deste estudo, 11 entre 14 informaram ter solicitado uma pessoa de sua escolha para acompanhar o trabalho de parto e o parto. Levando em consideração o vínculo entre a puérpera e a pessoa escolhida, observou-se que a presença da mãe foi solicitada por sete mulheres, enquanto as outras quatro foram acompanhadas por amiga, companheiro, cunhada e sogra. As três que vivenciaram o processo parturitivo sozinhas apresentaram como justificativa a impossibilidade de algum acompanhante comparecer ao hospital por estar cuidando de outros filhos ou trabalhando.

Quanto à importância atribuída pelas entrevistadas à presença de acompanhante durante o trabalho de parto e parto, identificou-se como núcleo de sentido "não se sentir só", apresentado nas falas de várias puérperas:

É bom para a gente ter alguém por perto, a gente não se sente só [...]. (Angélica) 
Eu acho bom para a gente não se sentir só [...] é um momento que dá um medo muito grande. Na hora das dores é sempre bom ter alguém com a gente. (Cecília)

É bom pra não se sentir sozinha [...] é ruim ficar sentindo dor e não ter ninguém para estar lá, do lado. (Daniela)

Foi bom, porque dessa vez demorou muito [o parto], ai ela [a sogra] ficou lá comigo, para eu não ficar só. (Eliana)

Tem maternidade que a gente vai para a sala [de parto] e deixam a gente sozinha e é muito dificil ficar ali sozinha, sofrendo. (Ingrid)

\section{Alguém conhecido e em quem pudessem confiar}

Verificou-se que das 11 puérperas que tiveram o trabalho de parto e o parto acompanhados, apenas uma não escolheu um membro da família para desempenhar esse papel. Depreende-se desse fato que, para as mulheres, a presença de alguém que seja conhecido, da família e em quem possam confiar também é levado em conta nessa escolha:

A gente não se sente só, porque tem uma pessoa que a gente conhece pertinho. (Angélica)

[...] poder ter alguém que a gente conhece e a gente pode confiar na pessoa é bom demais, e pode ser qualquer pessoa que a gente quiser. (Cecília)

É muito melhor ter uma pessoa próxima, que a gente gosta e que gosta da gente. (Ingrid)

Helena contou em seu depoimento que a presença de um acompanhante foi uma possibilidade de comunicação, uma vez que a cultura do silêncio durante o processo de parturição continua presente:

É bom porque [ela] já conhece. Quando a gente não conhece, a gente fica só olhando e não diz nada, com medo. (Helena)

\section{Atividades desempenhadas pelos acompanhantes}

Os depoimentos de Angélica, Daniela, Helena e Natália detalham a forma de participação dos acompanhantes durante o trabalho de parto e parto. Entre as atividades citadas por elas, destacam-se: conversar, proporcionar segurança para amenizar o medo, dar atenção, segurar a mão, explicar acontecimentos inerentes à parturição e preocupar-se com o bebê:

[O acompanhante] participa ajudando, falando com a gente, dizendo que vai dar tudo certo. (Angélica)

É bom porque a pessoa [acompanhante] fica lá com você e você pode falar com ela. (Helena)

É bom para não se sentir sozinha, para dar atenção, para conversar. (Daniela)

[...] tem uma pessoa perto, segurando a mão e explicando tudo, e se preocupando. É melhor do que ficar aqui sozinha, com certeza! (Natália)

\section{A presença de acompanhante não é importante}

A necessidade de acompanhante não foi considerada importante para todas as puérperas deste estudo, o que pôde ser percebido por meio da leitura dos depoimentos de Géssica e Olívia:

Eu acho que [a presença do acompanhante] não é importante, não. Nem na minha outra menina, que eu era menor de idade, eu não senti falta. (Géssica)

Eu acho besteira [a presença do acompanhante], porque quem vai ter [a criança] é você mesmo, quem vai sentir a dor é você, não é ninguém! Eu acho que tanto faz isso. (Olívia)

Ressalta-se que Géssica e Olívia experienciaram a parturição acompanhadas apenas pelos profissionais da equipe devido à impossibilidade do comparecimento de outra pessoa. Apesar de afirmar que não sentiu falta da presença de alguém de sua escolha, Géssica, ao responder o questionamento sobre a importância da presença de acompanhante, completou seu depoimento:

Só ia ser bom se [a acompanhante] fosse minha mãe, porque é a mãe da gente, você sabe, não é? Mas ela não pôde, porque ficou com a minha filha. Se fosse a minha mãe, eu queria, claro! (Géssica)

\section{DISCUSSÃO}

Acredita-se que as vivências de trabalho de parto e parto de mulheres que tiveram a oportunidade de ter alguém de sua escolha durante esses momentos são diferentes das que vivenciaram essas experiências 
sozinhas, mesmo que os profissionais envolvidos no processo ofereçam o cuidado e conforto necessários.

$\mathrm{O}$ respeito à escolha da mulher sobre seu acompanhante é classificado como uma prática comprovadamente útil e que deve ser estimulada. A viabilização desse direito da mulher reduz a necessidade de analgesia, a incidência de cesáreas e a depressão do recém-nascido no quinto minuto de vida. Além disso, essa experiência de apoio é um elemento importante na parturição, pois remete à mulher a sensação de tranquilidade, confiança e segurança ${ }^{(10-12)}$.

Ao analisar os acompanhantes quanto ao sexo, verificou-se que 10 eram do sexo feminino. Um estudo sobre a análise do perfil de acompanhantes verificou que $75 \%$ deles correspondiam ao sexo feminino e concluiu que isso se deve à condição de origem do evento (parto) que é essencialmente feminina. Na tradição, a gravidez, o parto e a maternidade são atributos de exclusividade da mulher, não sendo permitida a participação de homens ${ }^{(13)}$.

Sabe-se que a somente a presença do acompanhante não representa, em si, uma forma de suporte. Contudo, o fato de ter alguém para compartilhar o momento de dificuldade vivenciado foi considerado importante para essas mulheres. Elas mencionaram, em algumas falas, a necessidade de dividir a experiência, que descrevem como de dor e de sofrimento, como se o fato de ter alguém ao lado contribuísse pelo menos para amenizar a sensação de solidão. Inserir o acompanhante na sala de parto constitui um dos métodos não farmacológicos para a redução da dor, seja ele escolhido pela própria mulher ou por outra pessoa treinada para tal (doula); a presença desse acompanhante é capaz de promover bem-estar emocional e físico ${ }^{(10,14)}$.

Percebe-se que escolher o acompanhante para vivenciar o nascimento do filho ultrapassa o significado de companhia, pois o que se verifica é a importância que as participantes deste estudo atribuíram ao vínculo com a pessoa escolhida. A confiança se apresenta como pré-requisito, pois, para elas, o nascimento deve ser compartilhado com alguém que perceba a singularidade desse momento tão especial. A escolha de familiares para vivenciar esse momento se deve, em parte, à existência de uma convenção social de que, em situações como o parto e o nascimento, o esperado é que se escolha alguém da família ${ }^{(13,15)}$.

A sensação de solidão devido ao medo de se comunicar com outras pessoas presentes na sala de parto, como os profissionais, ainda se mostra evidente. Permanecer ao lado de pessoas desconhecidas durante o trabalho de parto e o parto desperta, em algumas mulheres, sentimentos negativos. Por isso, a presença de alguém conhecido, nesses momentos, se mostra como uma alternativa segura para o estabelecimento de comunicação e vínculo com os demais. Pessoas conhecidas proporcionam às parturientes oportunidade de expressão sem ameaças, pois o sentimento de solidão as torna vulneráveis, enquanto a presença do outro lhes dá suporte para a liberdade de expressão.

As falas evidenciam que a participação do acompanhante tornou o processo do nascimento mais tranquilo, pois o apoio proporcionado permitiu que a parturiente se sentisse mais segura pela presença de outra pessoa que colaborou ativamente com suas necessidades de cuidado. O acompanhante contribui, ainda, com a mudança da concepção do parto, tanto para as mulheres que o vivenciam, como para os profissionais, que têm a possibilidade de encará-lo de forma mais humana e menos técnica. $\mathrm{O}$ acompanhante apresenta atitudes que foram relevadas ao longo dos anos, como o interesse pelos sentimentos da mulher e o toque, representado pelo ato de segurar a mão. Além dessas atitudes, outras podem ser realizadas, como massagens, auxílio no banho de aspersão/imersão, na deambulação e encorajamento no período expulsivo ${ }^{(10)}$.

Situações que proporcionam à mulher relaxamento, informações e contato com uma pessoa de sua confiança, fazem-na se sentir mais confortável para vivenciar o nascimento do filho. A possibilidade de desfrutar de situações de cuidado e conforto, principalmente aquelas oferecidas por pessoas com as quais ela possui vínculo, gera elevação da autoestima e sensação de apoio, que resultam em satisfação e segurança. $\mathrm{O}$ alcance do bem-estar acontece quando a parturiente se sente amada e respeitada.

Verificou-se que três mulheres vivenciaram o trabalho de parto e o parto sem a presença de acompanhantes. Foi identificada uma lacuna na literatura no que concerne às pesquisas com mulheres que optaram por vivenciar o trabalho de parto e o parto sozinhas. Os poucos estudos sobre a percepção de parturientes/puérperas acerca dessa temática abordam apenas a percepção das que vivenciaram o processo parturitivo acompanhadas ou daquelas que desejariam compartilhar esse momento com alguém, nos casos de instituições que não cumprem a legislação brasileira.

Ao citar a presença da mãe como uma possibilidade para a mudança de opinião, uma das puérperas, que não solicitou a presença de acompanhante, revelou que a pessoa que confiava para dividir o momento do 
nascimento de seu filho era a sua mãe. Conforme já discutido, a confiança se apresenta como pré-requisito para a escolha do acompanhante, pois a existência de vínculo constitui a diferença entre qualquer pessoa e a pessoa desejada.

A escolha da mãe pela maioria das participantes, ou mesmo a manifestação desse desejo, revela que o momento de apoio é marcado pela troca de informações sobre experiências como o nascimento de um filho. Quem melhor poderá compreender as dificuldades e os sentimentos vivenciados do que a própria mãe, que também sofreu para dar à luz? As parturientes reconheceram na mãe os atributos que serão importantes para o relacionamento com o ser que está por vir; portanto, as mulheres levam em consideração as experiências vividas por quem as acompanham.

Observou-se, ainda, que a responsabilidade da maternidade e dos fenômenos nela envolvidos foi reconhecida como de exclusividade da mulher, pois é ela quem gesta, pare e cuida. Destaca-se que a ideia da responsabilidade individual da mulher pela gestação e pelo nascimento se configura como um entrave para a humanização do parto, pois algumas vezes há certa dificuldade em inserir a família nesse contexto.

O parto deve ser reconhecido como um evento familiar e social de extrema relevância, o qual envolve valor ético e humanitário. Entretanto, como inserir a família num contexto em que a parturiente se vê como única responsável pelo evento e não reconhece a importância de compartilhá-lo com outros tem sido um fato questionado ${ }^{(2)}$.

Verifica-se, portanto, que apesar das lutas para garantir o direito de participação do acompanhante durante o trabalho de parto, parto e puerpério imediato, a individualidade de cada mulher deve ser respeitada, uma vez que as opiniões dos profissionais não devem se sobrepor às da protagonista desses eventos: a parturiente.

\section{CONSIDERAÇÕES FINAIS}

O estudo analisou as percepções de puérperas acerca da presença/participação do acompanhante durante o trabalho de parto e o parto, levando em consideração o contexto em que estavam inseridas. A importância da participação do acompanhante no processo de nascimento centrou-se na minimização dos sentimentos de solidão que se somavam às dores das parturientes. Verificou-se o valor atribuído pelas puérperas à escolha de pessoas conhecidas, com destaque às mães; algumas mulheres se mostraram indiferentes à ausência de acompanhantes.
Evidenciou-se que somente a presença do acompanhante não foi considerada como suporte para as mulheres em trabalho de parto e parto. O diferencial girou em torno das atitudes que os acompanhantes tiveram para proporcionar conforto a elas.

Conclui-se que o cuidado, seja proporcionado pelos profissionais de saúde, seja pelos acompanhantes, mostra-se imprescindível para garantir conforto e bem-estar para mulheres no momento da parturição. Analisar as descrições das experiências de trabalho de parto e parto com a presença de alguém de sua escolha contribuiu para a compreensão do significado desses momentos para as parturientes. Refletir sobre a percepção de cada mulher quanto à vivência desses momentos auxilia na escolha de estratégias de cuidado que possam atender as necessidades individuais. A partir da descoberta das particularidades é que o cuidado pode ser planejado e construído, sempre com a finalidade de atender a parturiente de maneira integral.

Propõe-se que os familiares e/ou outras pessoas escolhidas pela mulher possam ser inseridas no contexto da gestação desde a primeira consulta pré-natal, para que possam se sentir melhor preparados para acolher e apoiar as parturientes em suas reais necessidades, pois a simples presença no momento do parto não se mostra suficiente para as mulheres.

\section{REFERÊNCIAS}

1. Oliveira ASS, Rodrigues DP, Guedes MVC, Felipe GF. Percepção de mulheres sobre a vivência do trabalho de parto e parto. Rev RENE. 2010;11(n.esp):32-41.

2. Bezerra MGA, Cardoso MVLML. Fatores interferentes no comportamento das parturientes: enfoque na etnoenfermagem. Rev Bras Enferm. 2005;58(6):698702.

3. Teixeira NZF, Pereira WR. Parto hospitalar experiências de mulheres da periferia de Cuibá-MT. Rev Bras Enferm. 2006;59(6):740-4.

4. Santos DS, Nunes IM. Doulas na assistência ao parto: concepção de profissionais de enfermagem. Esc Anna Nery. 2009;13(3):582-8.

5. Brasil. Lei n. 11.108, de 5 de abril de 2005. Altera a Lei n. 8.080, de 19 de setembro de 1990, para garantir às parturientes o direito à presença de acompanhante durante o trabalho de parto, parto e pós-parto imediato, no âmbito do Sistema Único de Saúde. Diário Oficial da República Federativa do Brasil, Brasília, 05 abr. 2005. 
6. Longo CSM, Andraus LMS, Barbosa MA. Participação do acompanhante na humanização do parto e sua relação com a equipe de saúde. Rev Eletr Enferm. [Internet] 2010;12(2) [acesso em 31 ago 2010]. Disponível: http://portais.ufg.br/projetos/fen_revista/ v12/n2/pdf/v12n2a25.pdf

7. Fontanella BJB, Ricas J, Turato ER. Amostragem por saturação em pesquisas qualitativas em saúde: contribuições teóricas. Cad Saúde Pública. 2008;24(1):17-27.

8. Bardin L. Análise de conteúdo. $5^{\mathrm{a}}$ ed. rev. atual. Lisboa: Edições 70 Persona; 2009.

9. Ministério da Saúde (BR). Conselho Nacional de Saúde. Diretrizes e normas regulamentadoras de pesquisa envolvendo seres humanos. Resolução n. 196, de 10 de outubro de 1996. Brasília; 1996.

10. Brüggemann OM, Parpinelli MA, Osis MJD. Evidências sobre o suporte durante o trabalho de parto/ parto: uma revisão da literatura. Cad Saúde Pública. 2005;21(5):1316-27.

11. Porfírio AB, Progianti JM, Souza DOM. As práticas humanizadas desenvolvidas por enfermeiras obstétricas na assistência ao parto hospitalar. Rev Eletr Enferm. [Internet] 2010;12(2) [acesso em 31 ago 2010]. Disponível: http://portais.ufg.br/projetos/fen_revista/ v12/n2/pdf/v12n2a16.pdf

12. Rosa R, Martins FE, Gasperi BL, Monticelli M, Siebert ERC, Martins NM. Mãe e filho: os primeiros laços de aproximação. Esc Anna Nery. 2010;14(1):105-12.

13. Nakano MAS, Silva LA, Beleza ACS, Stefanello J, Gomes FA. O suporte durante o processo de parturição: a visão do acompanhante. Acta Paul Enferm. 2007;20(2):131-7.

14. Carraro TE, Knobel R, Radünz V, Meincke SMK, Fiewski MFC, Frello AT, et al. Cuidado e conforto durante o trabalho de parto e parto: na busca pela opinião das mulheres. Texto \& Contexto Enferm. 2006;15(n.esp):97-104.

15. Alexandre AMC, Martins M. A vivência do pai em relação ao trabalho de parto e parto. Cogitare Enferm. 2009;14(2):324-31. 